\title{
Author Correction: Understanding the role of selenium in defect passivation for highly efficient selenium-alloyed cadmium telluride solar cells
}

Thomas A. M. Fiducia, Budhika G. Mendis, Kexue Li, Chris R. M. Grovenor, Amit H. Munshi, Kurt Barth,

Walajabad S. Sampath, Lewis D. Wright (D), Ali Abbas, Jake W. Bowers (D) and John M. Walls $\mathbb{D}$

Correction to: Nature Energy https://doi.org/10.1038/s41560-019-0389-z, published online 13 May 2019.

In the version of this Article originally published, the following text was missing from the 'Cell fabrication and electrical testing' section of the Methods: 'The CdTe and CdSeTe materials were provided by $5 \mathrm{~N}$ Plus.' It has now been added after the sentence starting "This was followed by $1.5-2.0 \mu \mathrm{m}$ of CdSeTe..." 